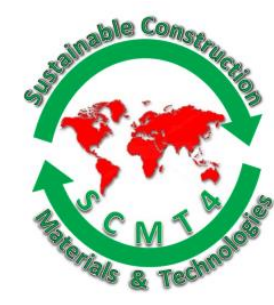

SCMT4

Las Vegas, USA, August 7-11, 2016

\title{
A Comprehensive Study on Hydrogen Embrittlement and Corrosion Propagation in Mild Steel Bridges
}

\author{
Le Li*1a, Mojtaba Mahmoodian' ${ }^{1 b}$, Shiwei Zhou ${ }^{1 c}$ and Chun Qing Li ${ }^{1 d}$ \\ ${ }^{1}$ School of Engineering; RMIT University, GPO Box 2476, Melbourne, VIC, Australia. \\ 1aEmail: <s3500237@student.rmit.edu.au>, ${ }^{1 b}$ Email: <mojtaba.mahmoodian@rmit.edu.au>, \\ ${ }^{1 c}$ Email:<shiwei.zhou@rmit.edu.au>, ${ }^{1 d}$ Email: <chunqing.li@rmit.edu.au>
}

\begin{abstract}
Despite of the vast research conducted on steel corrosion cracking, there are very limited technically rigorous explanations on hydrogen damage crack initiation and propagation in mild steel structural members. The intention of this paper is to study the hydrogen embrittlement effect on mild steel properties by a series of lab experiments and also to investigate the combined effect of stress and corrosion on mechanical properties of mild steel. Besides, the paper aims to develop and calibrate the matlab code on Extend Finite Element method for crack propagation. A test plan is designed to expose mild steel samples to corrosion and stress combination environment, with mass loss and hydrogen concentration monitored during corrosion. The paper provides a more accurate understanding of corrosion cracking propagation mechanism for mild steel bridges. The developed results can be used in bridge maintenance and assessment models.
\end{abstract}

\section{INTRODUCTION}

Hydrogen embrittlement effect on mild steel bridges is becoming an interesting topic in construction engineering [Djukic et al. 2014]. The hydrogen damage leads to unpredictable brittle cracking by degrading its mechanical properties [Revie 2008]. In details, this embrittlement reduces the ductility and tensile capacity of steel and makes it vulnerable to mode I cracking [Eggum 2013].

It is crucial to understand mechanisms of hydrogen assisted crack initiation and propagation. Hydrogen is released during the corrosion progress. To be specific, oxygen reduction reaction and hydrogen evolution reaction happen simultaneously during corrosion process [Stroe 2006]. These electro chemical reactions are summarized by Stroe [2006] from Eq. 1 to Eq.4. The proton $\left(\mathrm{H}_{3} \mathrm{O}^{+}\right)$that released from corrosion reaction contains hydrogen atoms $\left(\mathrm{H}^{+}\right)$. The hydrogen atoms are then absorbed by steel, leading to hydrogen embrittlement [Revie 2008; Stroe 2006; Eggum 2013].

Oxygen Reduction Reaction (ORR):

$$
\begin{array}{ll}
1 / 2 \mathrm{O}_{2}+2 \mathrm{H}_{3} \mathrm{O}^{+}+2 e \rightarrow 3 \mathrm{H}_{2} \mathrm{O} & \text { Acid } \\
1 / 2 \mathrm{O}_{2}+\mathrm{H}_{2} \mathrm{O}+2 e \rightarrow 2 \mathrm{OH}^{-} & \text {Neutral, alkaline }
\end{array}
$$


Hydrogen Evolution Reaction (HER):

$$
\begin{array}{ll}
\mathrm{H}_{3} \mathrm{O}^{+}+e \rightarrow 1 / 2 \mathrm{H}_{2}+\mathrm{H}_{2} \mathrm{O} & \text { Acid } \\
\mathrm{H}_{2} \mathrm{O}+e \rightarrow 1 / 2 \mathrm{H}_{2}+\mathrm{OH}^{-} & \text {Neutral, alkaline }
\end{array}
$$

Hydrogen-induced cracking in mild steels initiates when steel is embrittled under loading and corrosion combination environment [Shreir 2013]. Furthermore, the corrosion rate is likely to be affected by stress effect [Ramamurthy and Atrens 2010]. Few experiments have simulated this joint environment. In the current research, for stress-corrosion cracking analysis, steel samples are pre-stressed and then immersed in acidic solutions. These tests therefore provide an inspiration on creating load and corrosion combination environment to analyze the stress effect on corrosion rate. The most common solutions for hydrogen damage simulation is hydrochloride acid $(\mathrm{HCl})$ [Eggum 2013]. Nonetheless, previous researches charged hydrogen into steel by de-aerated acid solutions [Eggum 2013]. These tests ignored the oxygen reduction reaction during corrosion. Consequently, they failed to simulate a realistic corrosion environment in which steel is exposed to.

In this paper, both pre-stressed and none pre-stressed mild steel samples are immersed in hydrochloride acid solutions. The hydrogen content within the samples is measured using Barnacle cell [Mansfeld and Roe 1980]. In addition, tensile tests are also conducted to investigate the changes on mechanical properties under different corrosion rate and hydrogen concentration [Eggum 2013].

Besides those methodologies, Extend Finite Element Method (XFEM) is also used for investigating crack propagations mechanism. This method simulates crack growth without need to remesh the model [Pais et al. 2010]. Pais [2011] developed his Matlab code based on XFEM on crack propagation. However, the code has not been calibrated from experiments for hydrogen embrittlement crack cases. In this research, the Matlab code will be calibrated by lab experimental data obtained from observation of crack propagation during tensile tests.

The intention of this paper is, therefore, to conduct a comprehensive study on mild steel corrosion. To be more specific, the paper aims to quantify degrading effect of hydrogen on mechanical properties of steel. The effect of stress on corrosion progress will also be evaluated by creating stress-corrosion combination environment. Last but not least, this paper also monitors the crack growth during tensile tests and uses it to calibrate the developed XFEM Matlab code.

\section{EXPERIMENT CONCEPT}

Previous experiments conducted mechanical tests on hydrogen charged samples. The charging solution was de-aerated hydrogen chloride or sulfuric acid [Banerjee and Chatterjee 2001; Eggum 2013]. These tests ignored the oxygen reduction reaction during corrosion, and failed to deliver the corrosion rate and hydrogen concentration relationships. Besides, These previous experiment seldom considered stress effect on corrosion rate and hydrogen concentration [Ćwiek 2009].

As a novelty in the current research, steel will be pre-stressed with constant load during corrosion to investigate the combine effect of stress and corrosion. In addition, samples are immersed in common acid solution instead of de-aerated charging solution. In this way, the oxygen reduction reaction is considered, which simulates the corrosion of steel in realty.

\section{TEST SPECIMENS AND PRE STRESS APPLICATION}

The test specimens were taken from Grade 350 mild steel. This type of steel is commonly used for construction of bridges and other common steel structures. Samples shapes were designed based on 
tensile test specimen requirements referring to ASTM E8. The chemical components of the steel samples and their shape design are shown as Table 1 and Figure 1, respectively. The enlarged ends of tensile test samples were coated with epoxy paints to prevent their corrosion throughout experiments.

\section{Table 1. Chemical Component of G350 steel (weight \%)}

\begin{tabular}{|c|c|c|c|c|c|c|c|c|c|c|}
\hline $\mathrm{C}$ & $\mathrm{Si}$ & $\mathrm{Mn}$ & $\mathrm{P}$ & $\mathrm{S}$ & $\mathrm{Cr}$ & $\mathrm{Ni}$ & $\mathrm{Cu}$ & $\mathrm{Mo}$ & $\mathrm{Al}$ & $\mathrm{Ti}$ \\
\hline 0.22 & 0.55 & 1.70 & 0.04 & 0.03 & 0.25 & 0.5 & 0.4 & 0.35 & 0.1 & 0.04 \\
\hline
\end{tabular}
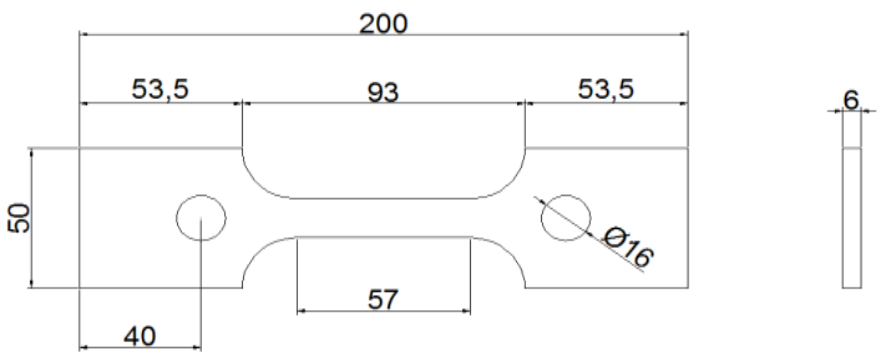

Figure 1. Test Sample Designed based on ASTM E8

A total number of 74 samples were prepared in which half of them will be pre-stressed. The prestressing will be $77 \%$ of the steel yield stress $(220 \mathrm{Mpa})$. This percentage was determined based on the ratio between serviceability load and ultimate load referring to AS1170.2.2011.

Pre-stressing of the samples will be achieved through clamp and jig system designed as Figure 2 . The systems are composed of two $1800 \mathrm{~mm} \times 30 \mathrm{~mm} \times 26 \mathrm{~mm}$ grade 904 stainless steel plates and four M16 high tensile steel screws. Samples will be stretched up to $220 \mathrm{Mpa}$ by tensile test machine and fixed by screws. The clamp and jig systems will also be coated with epoxy paints to prevent corrosion while they are immersed in acid.

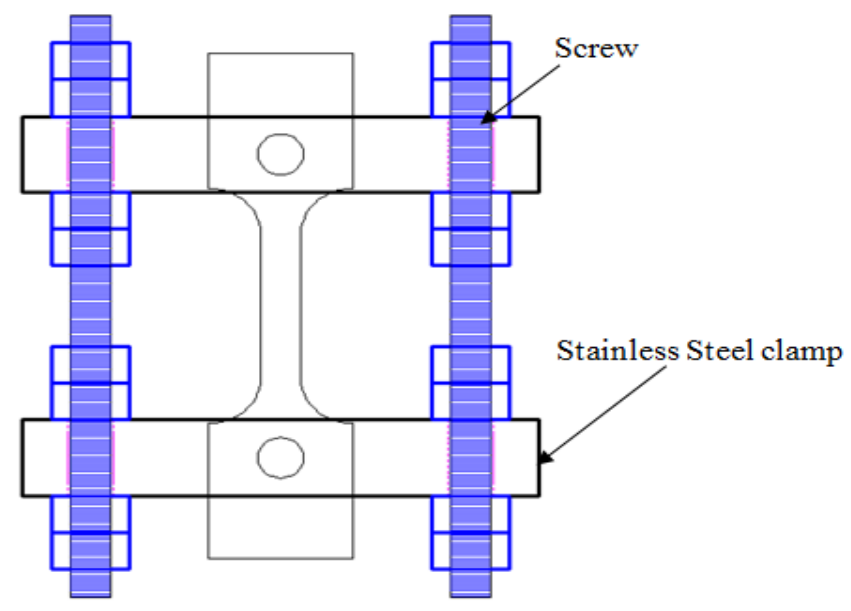

Figure 2. Clamp and Jig System Designed for Pre-stress Application

\section{CORROSION SIMULATION}

Samples are immersed into hydrochloride $(\mathrm{HCl})$ solutions at room temperature. Hydrochloride acid has been selected as the corrosive solution. It is more aggressive compare with other solutions, as chloride 
atoms breaks the passive layer of steel during corrosion [Loto 2013]. Moreover, two different concentrations for solutions including $1 \mathrm{M} \mathrm{HCl}$ and $2 \mathrm{M} \mathrm{HCl}$ were selected to investigate the hydrogen induced damage to steel under the two different corrosive environments. The immersion time were set as $120,240,360$ hours, suggested by ASTM G31. Samples were weighed before and after the immersion to determine mass loss as an indication of the corrosion degree.

After corrosion simulation, half of the samples will be selected for mechanical property test (i.e., tensile test) whilst the rest half will be taken for hydrogen concentration measurement. Details of the experiment plan are summarized in Table 2 .

Table 2. Test Plan and Sample Number of Tensile and Hydrogen measurement Test

\begin{tabular}{|c|c|c|c|c|}
\hline Temperature: & \multicolumn{4}{|c|}{ Room temperature $\left(25^{\circ} \mathrm{C}\right)$} \\
\hline \multirow{2}{*}{ Solution } & \multirow[t]{2}{*}{ Pre-stress } & \multirow{2}{*}{$\begin{array}{l}\text { Reaction time } \\
\text { (hours) }\end{array}$} & \multicolumn{2}{|c|}{ Sample number } \\
\hline & & & Tensile test & Hydrogen test \\
\hline \multirow[t]{7}{*}{$1 \mathrm{M} \mathrm{HCl}$} & \multirow[t]{4}{*}{0} & $0 \mathrm{~h}$ & 1 & 1 \\
\hline & & $120 \mathrm{~h}$ & 3 & 3 \\
\hline & & $240 \mathrm{~h}$ & 3 & 3 \\
\hline & & $360 \mathrm{~h}$ & 3 & 3 \\
\hline & \multirow[t]{3}{*}{ 220Мра } & $120 \mathrm{~h}$ & 3 & 3 \\
\hline & & $240 \mathrm{~h}$ & 3 & 3 \\
\hline & & $360 \mathrm{~h}$ & 3 & 3 \\
\hline \multirow[t]{6}{*}{$2 \mathrm{M} \mathrm{HCl}$} & \multirow[t]{3}{*}{0} & $120 \mathrm{~h}$ & 3 & 3 \\
\hline & & $240 \mathrm{~h}$ & 3 & 3 \\
\hline & & $360 \mathrm{~h}$ & 3 & 3 \\
\hline & \multirow[t]{3}{*}{ 220Mpa } & $120 \mathrm{~h}$ & 3 & 3 \\
\hline & & $240 \mathrm{~h}$ & 3 & 3 \\
\hline & & $360 \mathrm{~h}$ & 3 & 3 \\
\hline
\end{tabular}

\section{TENSILE TEST AND HYDROGEN MEASUREMENT}

Tensile test was conducted referred to ASTM E8. The cross head speed was set as $0.9 \mathrm{~mm} / \mathrm{s}$ for entire samples. Hydrogen concentration test were performed using Barnacle cell referring to ASTM F 1113-87. The method is nontoxic and relatively easy to conduct compare with traditional mercury displacement test [Mansfeld and Roe 1980]. Barnacle cell makes hydrogen-containing part as anode, while the cathode is a nickel/nickel oxide electrode. The system measures the oxidization current when protons $\left(\mathrm{H}^{+}\right)$reacts with hydroxyl ion $\left(\mathrm{OH}^{-}\right)$through electrometer. The setup of test is shown in Figure 3. The hydrogen concentration is calculated through Eq.5

$$
I_{p}=F C_{0}\left(\frac{D}{\pi t}\right)^{1 / 2}
$$

where $I_{p}$ is the current density, $\mathrm{F}$ is the Faraday constant $(96485.3 \mathrm{C} / \mathrm{mol}), C_{0}$ is the hydrogen concentration, $t$ is the recording time (30mins by standard), D is the diffusion coefficient ( $2.5 \times$ $10^{-8} \mathrm{~cm} / \mathrm{s}^{2}$ ). 


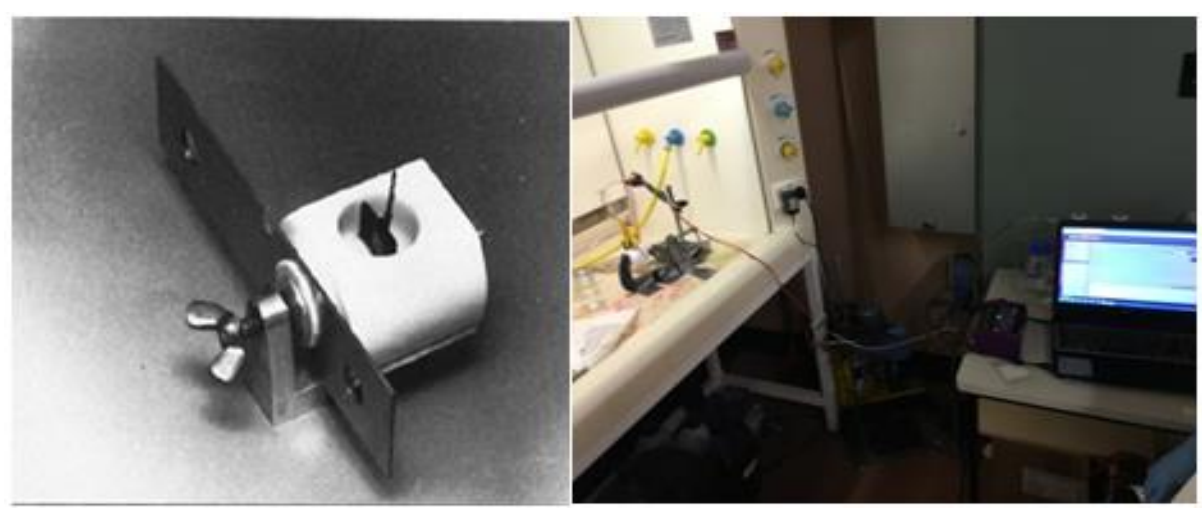

Figure 3. Barnacle Cell for Hydrogen Measurement (ASTM F 1113)

\section{NUMERICAL ANALYSIS}

The Extend Finite Element Method. Crack growth simulation can be conducted by using Extend Finite Element method (XFEM) [Pais et al. 2010]. This method uses enrichment function and level set method to simulate crack propagation. In general, the displacements for each finite element nodes in XFEM systems are summarized as Eq.6 [Sukumar et al. 2001; Pais et al. 2010].

$$
\boldsymbol{u}^{\boldsymbol{h}}(x)=\sum_{I \in \Omega} N_{I}(x)\left[\boldsymbol{u}_{I}+\sum_{I \in \Omega_{\mathrm{d}}} v(x) \boldsymbol{a}_{I}\right]
$$

In the above equation, $\Omega$ is the domain of the model and $\Omega_{\mathrm{d}}$ is the domain containing discontinuity (cracks). In addition, $N_{I}(x)$ are the shape functions for traditional finite elements, $v(x)$ is the enrichment function for crack, $\boldsymbol{u}_{\boldsymbol{I}}$ and $\boldsymbol{a}_{\boldsymbol{I}}$ are the traditional and enrichment degrees of freedom (DOF) [Pais 2011]. Enrichment functions are based on level set method [Pais 2010].

Level set method. Level set method tracks crack growth and allocates crack tips. For elements completely cut by crack, the Heaviside enrichment function $(h(x))$ is presented as Eq.7 [Pais et al. 2010; Sukumar et al. 2001].

$$
h(x)= \begin{cases}+1 & \text { above crack } \\ -1 & \text { below crack }\end{cases}
$$

For an element containing crack tip, the asymptotic functions are presented including four separate functions, as Eq.8.

$$
\left\{\phi_{\alpha}(x)\right\}_{1 \leq \alpha \leq 4}=\left\{\sqrt{r} \sin \frac{\theta}{2}, \sqrt{r} \cos \frac{\theta}{2}, \sqrt{r} \sin \frac{\theta}{2} \sin \theta, \sqrt{r} \cos \frac{\theta}{2} \sin \theta\right\}
$$

where $r$ and $\theta$ are the polar coordinates referring respectively to crack-tip. The enrichment theory is illustrated in Figure 4. To be specific, nodes next to crack growth path and crack tips are enriched by Eq.7 and Eq.8, respectively. This procedure allows mesh to be relocated during crack growth, and calculates the stress and displacement around cracks [Patricio and Mattheij 2007; Pais et al. 2010].

Voids are also meshed independently in XFEM to allow complex shape inputs. The enrichment function for voids is shown as Eq.9 where $V(x)$ is the voids enrichment. Mechanical properties for steel are defined as zero inside void region [Sukumar et al. 2001].

$$
\boldsymbol{u}^{\boldsymbol{h}}(x)=V(x) \sum_{I \in \Omega} N_{I}(x)
$$


The general enrichment function for Eq. 6 is reordered based on Eq.7, Eq.8 and Eq.9 [Pais et al. 2010]. The formulation can be shown as Eq.10.

$$
\boldsymbol{u}^{\boldsymbol{h}}(x)=V(x) \sum_{I \in \Omega} N_{I}(x)\left[\boldsymbol{u}_{\boldsymbol{I}}+\sum_{I \in \Omega_{H}} H(x) \boldsymbol{a}_{I}+\sum_{I \in \Omega_{T}} \sum_{\alpha=1}^{4} \phi_{\alpha}(x) \boldsymbol{b}_{I}^{\alpha}\right]
$$

In Eq.10, $\Omega_{H}$ is the domain cut by crack, $\Omega_{T}$ is the domain where crack tip allocates, $H(x)$ is the shifted Heaviside enrichment, whilst $\phi_{\alpha}(x)$ is the shifted crack tip enrichment. $\boldsymbol{a}_{\boldsymbol{I}}$ is the enriched degree of freedom along crack path and $\boldsymbol{b}_{\boldsymbol{I}}$ is the enriched degree of freedom at crack tips.

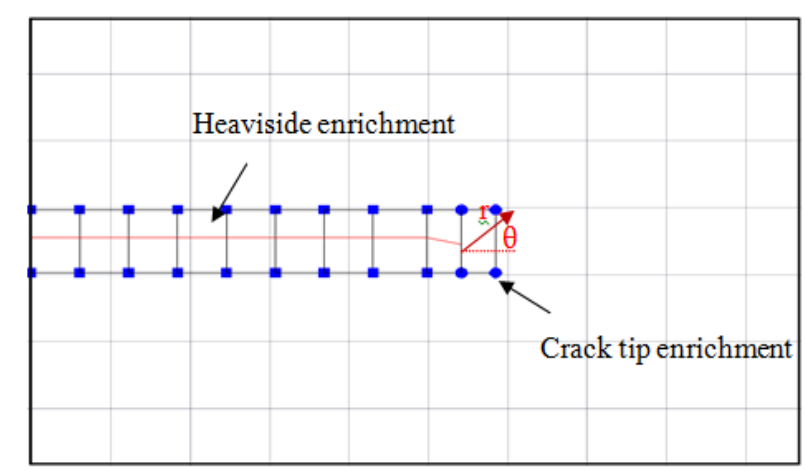

\section{Figure 4. Enrichment Strategy for Crack Tip (circle) and Crack Path (square)}

Stiffness matrix. Displacement and stress are calculated by global stiffness matrix, with related calculations defined as Eq. 11 [Pais et al. 2010].

$$
[K] u=f
$$

To be specific, $\boldsymbol{K}$ is the global stiffness matrix, $\boldsymbol{u}$ is the global degree of freedom and $\boldsymbol{f}$ is the applied loading [Pais 2011]. The stiffness matrix can be written as Eq.12.

$$
K=\left[\begin{array}{lll}
K_{u u} & K_{u a} & K_{u b} \\
K_{u a}^{T} & K_{a a} & K_{a b} \\
K_{u b}^{T} & K_{a b}^{T} & K_{b b}
\end{array}\right]
$$

where $\boldsymbol{u}$ represents the traditional stiffness matrix, $\boldsymbol{a}$ refers to the Heaviside enrichment values, and $\boldsymbol{b}$ indicates the crack tip enrichment values [Pais et al. 2010]. The calculation of each element in stiffness matrix is referred to Eq.13

$$
K_{\alpha, \beta}=\int_{\Omega} B_{\alpha}{ }^{T} C B_{\beta} d \Omega \quad \alpha, \beta=u, a, b
$$

In Eq.13, $\boldsymbol{C}$ is the tangent modulus tensor, and $\mathbf{B}$ is the shape function derivation matrix, the details for calculation of $\mathbf{C}$ and $\mathbf{B}$ are given in Sukumar [2001].

Crack growth. Propagation direction for hydrogen assisted crack is determined by maximum circumferential stress criteria [Pais et al. 2010]. In general, crack growth angle based on maximum circumferential stress criteria is shown as Eq.14.

$$
\theta_{c}=2 \arctan \frac{1}{4}\left\{\frac{K_{I}}{K_{I I}}-\operatorname{sign} K_{I I} \sqrt{\left(\frac{K_{I}}{K_{I I}}\right)^{2}+8}\right\}
$$


$\theta_{c}$ is the crack growth angle according to crack tip coordinate system. $K_{I}$ and $K_{I I}$ are the stress intensity factors for Mode I and Mode II crack, respectively. To be specific, only $K_{I}$ is considered since hydrogen assisted crack is Mode I crack in most of the cases.

For crack growth rate, the Paris crack growth model can determine crack growth rate [Pais et al. 2010]. The equation is shown as Eq. 15.

$$
\frac{d a}{d N}=C N \Delta K^{m}
$$

where $\frac{d a}{d N}$ is the crack growth rate, $a$ is the crack length and $\mathrm{N}$ is the number of load cycles, $\Delta K$ is the stress intensify factor range $\left(\Delta K=K_{\max }-K_{\min }\right), \mathrm{C}$ and $\mathrm{m}$ are the material scale constant. The calculation of stress intensity factor is based on Contour integral method, shown as Eq.16.

$$
J=\frac{K_{I}^{2}}{E_{e f f}}+\frac{K_{I I}^{2}}{E_{e f f}}
$$

where $E_{\text {eff }}$ is the effective Young's Modules defined by Eq.17 [Hertzberg 1989] .

$$
E_{\text {eff }}= \begin{cases}E & \text { Plane stress } \\ \frac{E}{1-v^{2}} & \text { Plane strain }\end{cases}
$$

$E$ is the Young's modulus and $v$ is the Poisson's ratio. $\mathrm{J}$ is the J-integral representing energy release rate, defined as Eq.18 [Hertzberg 1989; Rice 1968].

$$
J=\int_{\Gamma}\left(W d y-T \frac{\partial u}{\partial x} d s\right)
$$

where $\mathrm{W}$ is the strain energy density, ds is the increment along contour, $\boldsymbol{T}$ is the stress vector on the contour $\left(T_{i}=\sigma_{i j} n_{j}\right)$, and $\boldsymbol{u}$ is the displacement factor, $\Gamma$ is the contour around the crack tip indicated by Figure 5 .

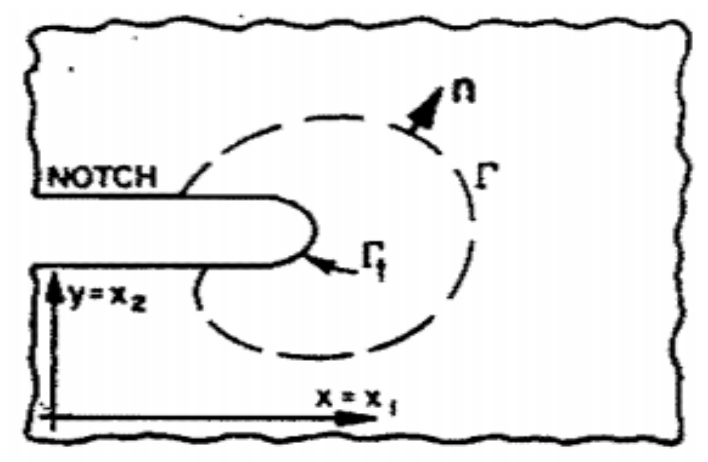

Figure 5. J integral Contour $\Gamma$ and Nominal Vector $\overrightarrow{\boldsymbol{n}}$ on Contour Path [Hertzberg 1989; Rice 1968]

Model set up. Crack growth simulation and numerical calculation were conducted by XFEM using Matlab. The code was developed based on Eq.6 to Eq. 18 referring to Pais et al. [2010]. A Grade 350 mild steel plate with shape shown as Figure 6 was modeled. The plate was subjected to $1 \mathrm{~N} / \mathrm{mm}$ tensile force at one end and fixed at the other. A crack was predefined at the point where stress is maximum. The initial crack length was $3 \mathrm{~mm}$. The input Young's moduls is $200 \mathrm{Gpa}$ and the poisson ratio was 0.25 . Steel was modelled as linear elastic material by assuming the embrittlement effect of hydrogen. 


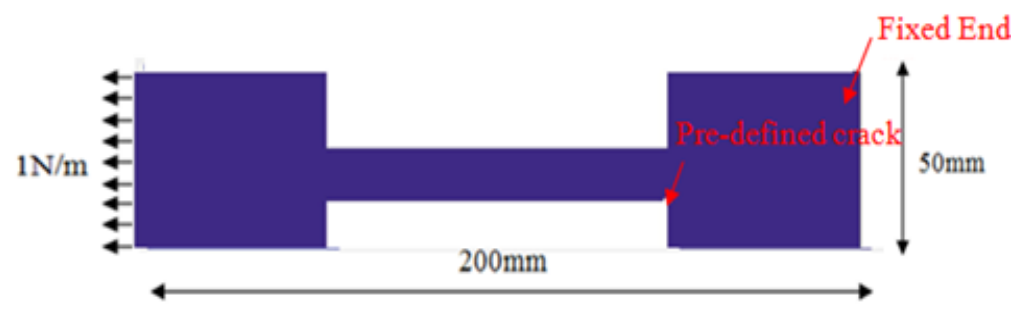

Figure 6. Tensile Specimen Modeled by XFEM with Predefined Crack

\section{RESULTS AND DISCUSSIONS}

The experiment is undergoing and therefore only primary results are summarized in this section. The corrosion rate for the first group of mild steel ( 6 samples) have been measured, with result summarized in Table 3. The average mass loss is $0.24 \%$ with standard deviation of 0.04 .

Table 3. Corrosion Rate for None Pre-stressed Sample during 120 Hour Immersion in 1M HCl

\begin{tabular}{|c|c|c|c|}
\hline $\begin{array}{c}\text { Sample } \\
\text { Number }\end{array}$ & Mass before corrosion (g) & Mass after corrosion (g) & Mass loss \% \\
\hline A & 311.90 & 311.28 & 0.20 \\
\hline B & 312.59 & 311.88 & 0.23 \\
\hline C & 313.57 & 312.67 & 0.29 \\
\hline D & 309.73 & 309.12 & 0.20 \\
\hline E & 314.36 & 313.43 & 0.30 \\
\hline F & 310.10 & 309.30 & 0.26 \\
\hline
\end{tabular}

Tensile test and hydrogen concentration test were conducted for the samples before and after corrosion; the tensile test results are shown in Figure 7. The mild steel has the yield stress of 325.1 MPa and the ultimate stress as 441.2MPa before corrosion. After exposure to corrosive solution for 120 hours, the yield stress dropped to $277 \mathrm{Mpa}$, and the ultimate stress reduced to $421 \mathrm{Mpa}$. In further tests, longer exposure time will be investigated to have more reliable data and estimate the change on mechanical properties with various corrosion rates.

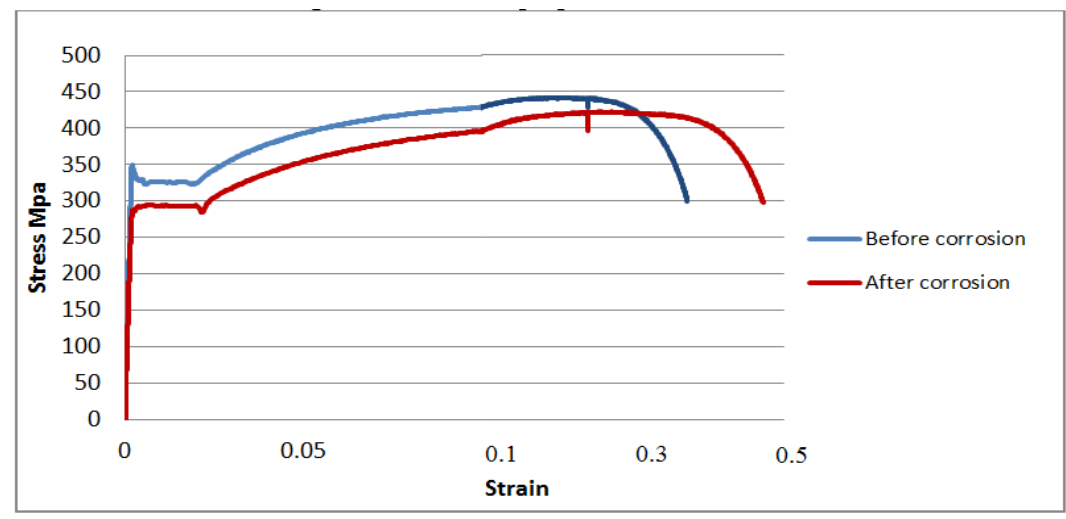

Figure 7. Tensile Test for Sample before Corrosion and after Corrosion

Hydrogen concentration measurement was conducted by measuring the voltage change on electrometers. The current was recorded during 30-min reading in Figure 8. The current density at the end of 30 minutes was $0.62 \mu \mathrm{A} / \mathrm{cm}^{2}$, leading to the hydrogen concentration of $0.41 \mathrm{ppm}$ based on Equation 5 . 


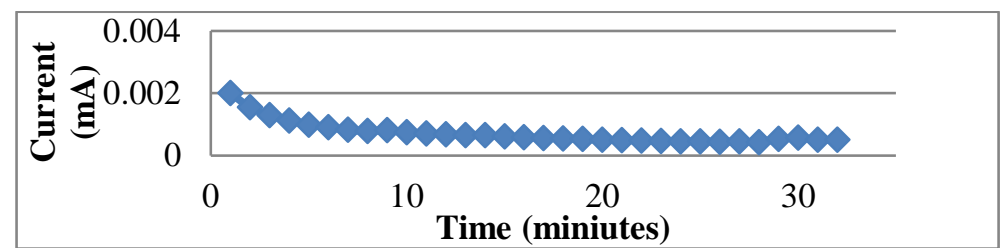

Figure 8. Current Change for Un-corroded Sample During 30-minite Reading

Crack propagation was simulated by XFEM. The calculation was achieved by Matlab referring to Pais [2011] and the total calculation lasted for 24 steps. The crack growth simulation is shown in Figure 9 for every 6 steps. For the next step, the crack propagation simulation will be compared with the crack growth recorded in tensile test for calibration.
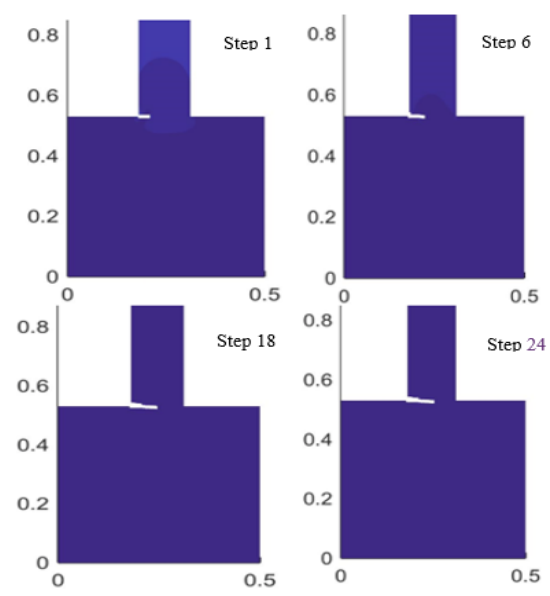

Figure 9. Crack growth simulation by XFEM method

\section{FURTHER WORK}

Further work is to immerse the rest of the samples (i.e., pre-stressed and none pre-stressed samples) in hydrochloride acid solutions. The immersion time would be 120, 240, 360 hours. Then, tensile tests and hydrogen measurement test will be conducted for the samples. It is expected that hydrogen concentration rises along with corrosion rate, and necking strain rate of mild steel reduces with increment of hydrogen concentration. Corrosion rate is also expected to be faster under stress and corrosion combination environment. In addition, the propagations of cracks will be monitored during tensile test. The results will be compared with current Matlab code, which simulates crack growth by Extend Finite Element method. In this way, the code will be calibrated and modified based on the experiment.

\section{CONCLUSION}

This paper presents part of a comprehensive study on the effect of hydrogen on mechanical properties of mild steel, the effect of stress on corrosion rate, and the development needed on XFEM Matlab code. The preliminary results indicate that corrosion affects the mechanical properties of steel, and Barnacle cell method is feasible to measure hydrogen concentration within steel. Moreover, the Matlab code developed is able to provide preliminary crack growth simulation. The comprehensive lab experiments are ongoing and it is expected to elaborate the degrading effect of hydrogen on mechanical properties of steel through the whole series of the tests. The stress effect on corrosion rate will also be quantified. 
Furthermore, crack growth will be monitored during tensile test and XFEM model will be calibrated based on the observed crack growth. In this way, a more accurate code on crack growth simulation will be developed.

\section{ACKNOWLEDGEMENT}

Financial support from Metro Trains Melbourne, Australia and Australian Research Council under DP140101547 and LP150100413 is gratefully acknowledged. Thanks are extended to Mr. Pavel Ryjkov, Ms. Peggy Chang, Mr. Kevin Le and the entire technical team in RMIT Civil lab and Chemistry lab for their help.

\section{REFERENCE}

ASTM E 8 / E 8 M-15. "Standard Test Methods for Tension Testing of Metallic Materials" ASTM International, West Conshohocken, PA, 29 pages.

ASTM F 1113-87. "Standard Test Method for Electrochemical Measurement of Diffusible Hydrogen in Steels (Barnacle Electrode)" ASTM International, West Conshohocken, PA, 2011,

ASTM G 31-72. "Standard Practice for Laboratory Immersion Corrosion Testing of Metals" ASTM International, West Conshohocken, PA, 8 pages.

Banerjee, K., and Chatterjee, U. (2001). "Hydrogen permeation and hydrogen content under cathodic charging in HSLA 80 and HSLA 100 steels. " Scripta Materialia, 44(2), 213-216.

Ćwiek, J. (2009). "Hydrogen degradation of high-strength steels. Journal of Achievements in Materials and Manufacturing Engineering." 37(2), 193-212.

Djukic, M., Zeravcic, V. S., Bakic, G., Sedmak, A., and Rajicic, B. (2014). "Hydrogen Embrittlement of Low Carbon Structural Steel.” Procedia Materials Science, 3, 1167-1172.

Eggum, T. J. (2013). "Hydrogen in Low Carbon Steel: Diffusion, Effect on Tensile Properties, and an Examination of Hydrogen's Role in the Initiation of Stress Corrosion Cracking in a Failed Pipeline." Doctoral dissertation, University of Calgary

Hertzberg, R. W. (1989). "Deformation and fracture mechanics of engineering materials.” 5th Ed., John Wiley \& Sons.

Loto, R. T. (2013). "Pitting corrosion evaluation of austenitic stainless steel type 304 in acid chloride media." J. Mater. Environ. Sci, 4(4), 448-459.

Mansfeld, F. B. and Roe, D. K., Rockwell International Corporation, 1980. Electrochemical cell for measuring hydrogen in metal. U.S. Patent 4,221,651.

Pais, M. (2011). "MATLAB Extended Finite Element (MXFEM) Code v1.2." <http: Ilwww.matthewpais.com> (Jan.8, 2013).

Pais, M., Kim, N.H., and Davis, T. (2010) "Reanalysis of the extended finite element method for crack initiation and propagation." Proceedings of AIAA Structures, Structural Dynamics, and Materials Conference.

Patrıcio, M. \& Mattheij, R. (2007). “Crack propagation analysis.” CASA report, 07-03.

Ramamurthy, S. \& Atrens, A. (2010). "The influence of applied stress rate on the stress corrosion cracking of 4340 and 3.5 NiCrMoV steels in distilled water at 30 C." Corrosion Science, 52(3), 1042-1051.

Revie, R. W. (2008). “Corrosion and corrosion control.” 4th Ed., John Wiley \& Sons.

Rice, J. R. (1968). “A path independent integral and the approximate analysis of strain concentration by 
notches and cracks." Journal of applied mechanics, 35(2), 379-386.

Shreir, L. L. ed., (2013). Corrosion: corrosion contro., Newnes.

Stroe, M. E. (2006). "Hydrogen embrittlement of ferrous materials." Universite Libre De Bruxelles.

Sukumar, N., Chopp, D.L., Moës, N. and Belytschko, T., (2001). "Modeling holes and inclusions by level sets in the extended finite-element method." Computer methods in applied mechanics and engineering, 190(46), 6183-6200. 